\title{
Una aproximación a la presencia de la «burla pesada» en las recreaciones narrativas hispánicas del Quijote

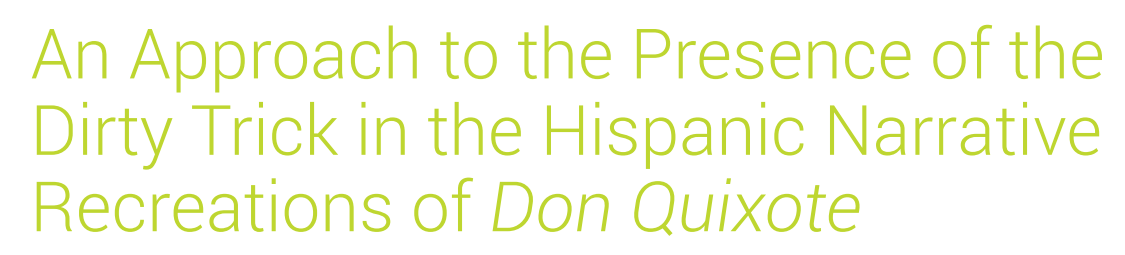

\section{Santiago López Navia}

Universidad Internacional de La Rioja /

ESPAÑA

Cátedra de Estudios Humanísticos Felipe Segovia Martínez

Universidad SEK, Santiago de Chile

CHILE

santiagoalfonso.lopeznavia@unir.net

[Hipogrifo, (issn: 2328-1308), 7.2, 2019, pp. 69-83]

Recibido: 30-05-2019 / Aceptado: 17-10-2019

DOI: http://dx.doi.org/10.13035/H.2019.07.02.07

Resumen. La burla pesada, caracterizada frente a la eutrapélica por sus intenciones vejatorias y en alguna ocasión por sus consecuencias físicas, se manifiesta en algunas obras pertenecientes al corpus de las recreaciones narrativas del Quijote en lengua española. Tras la pertinente delimitación de conceptos, en el presente artículo se estudia de forma sistemática la presencia de esta forma de burla en algunas continuaciones, imitaciones y ampliaciones de la novela original de Cervantes desde el siglo XVII hasta nuestros días.

Palabras clave. Burla pesada; recreaciones narrativas; Cervantes; Quijote.

Abstract. The dirty trick, characterized as opposed to the eutrapelic one because of its degrading intentions and occasionally because of its physical consequences, appears in any works belonging to the corpus of narrative Don Quixote's reception in Spanish. After defining concepts appropriately, in this article we propose a reasoned study concerning the presence of this kind of mockery in some 
continuations, imitations and additions of the original Cervantes' novel from XVIIth century to the present.

Keywords. Dirty trick; narrative recreations; Cervantes; Don Quixote.

\section{INTRODUCCIÓN Y MARCO CONCEPTUAL}

El hecho de que consideremos expresamente este trabajo como una primera aproximación no es solo una muestra de deseable prudencia, sino una consecuencia de las dificultades inherentes a un corpus extenso y abierto tanto en su determinación como en sus propias posibilidades creativas. En su determinación, porque resulta muy complejo establecer un inventario definitivo de las recreaciones narrativas del Quijote en el ámbito hispánico, empezando por la dificultad añadida que supone la diversidad de idiomas afectados por el repertorio, que no está solo escrito en español; en sus posibilidades creativas, porque prevemos que la modalidad de las recreaciones sigue y seguirá abierta, espoleada a veces por el impulso connatural a los aniversarios, pero vigente en toda ocasión, como demuestra la vasta cronología de la narrativa que recrea el original cervantino.

Al hablar de «burla» en las recreaciones narrativas hispánicas del Quijote nos atenemos a la diferencia que Pedrosa establece entre su naturaleza física y la propia de la agudeza, de carácter verbal:

La burla es una acción en que un personaje agrede cómicamente a otro, poniendo en juego su cuerpo y los objetos del entorno para obtener una reacción ridícula del oponente. La agudeza es una modalidad de la burla de carácter exclusivamente verbal, que opera mediante el solo instrumento de la palabra, y no de la acción corporal ${ }^{1}$.

Este concepto guarda una clara relación con la definición de «burla pesada» que propone Covarrubias: «la que es perjudicial y con daño de la persona a quien se hace $»^{2}$, y por lo tanto se opone claramente a la eutrapelia tal como la define Aristóteles en el libro IV, 8 de su Ética nicomaquea, que es la que cultivan quienes «procuran por todos los medios hacer reír y tienden más a provocar la risa, que a decir cosas agradables o a no molestar al que es objeto de sus burlas» ${ }^{3}$, tal como también la concibe Covarrubias al referirse a ella como «un entretenimiento de burlas graciosas y sin perjuicio» ${ }^{4}$.

1. Pedrosa, 2004, p. 249.

2. Covarrubias, Tesoro de la lengua castellana o española, p. 371

3. Aristóteles, Ética nicomaquea, p. 232.

4. Covarrubias, Tesoro de la lengua castellana o española, p. 864. Queda claro que el ámbito de nuestro estudio por una parte trasciende los Siglos de Oro y por otra se centra en una forma concreta de burla que hemos delimitado conceptualmente desde el principio. Las diferentes formas y manifestaciones de la burla en la literatura de los Siglos de Oro han sido estudiadas con singular acierto y detalle en el volumen de conjunto editado por Arellano y Roncero (2006). Remitimos especialmente a los atinados estudios de Arellano, Close y Roncero en él incluidos. 
En nuestro recorrido por las recreaciones narrativas del Quijote en la literatura hispánica diferenciaremos expresamente las tres categorías de nuestra clasificación ${ }^{5}$, ocupándonos en primer lugar de las que denominamos quijotescas, en tanto que se atienen al universo literario constituido por los personajes de la obra original (las continuaciones y las ampliaciones) y después de las quijotizantes, protagonizadas por personajes diferentes que replican las peripecias y aventuras del modelo (las imitaciones). Como veremos, no todas las recreaciones son humorísticas. Hay un buen número de ellas de registro deliberadamente grave y no pocas veces trágico, y en ellas la burla adquiere otra dimensión, en un sentido próximo al apuntado por Étienvre cuando dice precisamente que «lo burlesco no puede reducirse a las burlas» ${ }^{6}$.

La dimensión física y agresiva de la burla pesada frente a la eutrapelia o agudeza verbal resulta de especial relevancia en el estudio de las recreaciones narrativas hispánicas del Quijote, toda vez que en algunas de ellas la segunda prevalece sobre la primera. Es el caso del Quijote de Avellaneda, cuyas burlas son claramente consideradas eutrapélicas según Gómez Canseco? ${ }^{7}$. A este registro eutrapélico se adscriben también las burlas a las cuales es sometido Sancho Panza cuando es investido Barón de Casa Panza en el palacio ducal en las Adiciones de Jacinto María Delgado (1786), alguna burla del Quijote del siglo XVIII de Juan Francisco Siñeriz (1836) inspirada en la estancia de don Quijote en la casa de Antonio Moreno en Barcelona ${ }^{8}$, el sentido didáctico y moralizante que, con buen criterio, aprecia Martínez Fernández ${ }^{9}$ en la sátira que impregna el Fray Gerundio de Campazas del padre Isla (1758) o las que concita entre sus compañeros de armas el misterioso abanderado D. Q., en el cuento homónimo de Rubén Darío (1899).

En una línea parecida se encuentra el Quijote de la Cantabria de Ribero y Larrea (1792) en el que -aunque el protagonista, don Pelayo Infanzón de la Vega, suele salir airoso de los intentos de burla a los que le someten los demás personajes - no falta algún trance burlesco que remite a la estancia de don Quijote y Sancho Panza entre los duques (recuérdese el bloque comprendido entre los capítulos II, 30 y II, 57 del Quijote). Así, en el capítulo II, 15 conocemos la intención del duque de la Muela, anfitrión de Pelayo y su criado Mateo, de invitar a don Pelayo «a refrescar y pasear en coche con el fin de sonrojarlo» ${ }^{10}$ dejando en evidencia sus dislates.

\footnotetext{
5. López Navia, 1996, pp. 154-158.

6. Étienvre, 2004, p. 243.

7. Ver la «Introducción» a su edición del Quijote de Avellaneda (2014, pp. 66-74). Resulta de especial interés en este sentido la observación de Gómez Canseco sobre el uso de la palabra pieza para referirse a don Quijote y Sancho como «hombres de placer» para regocijo de la corte en el sentido que propone el Diccionario de autoridades.

8. A su paso por Orleans, en el capítulo II, 8, un estudiante cuelga en la espalda de Mr. Le-Grand un cartel con su nombre para que puedan leerlo quienes lo ven, de modo que crea que su fama es pública. 9. Martínez Fernández, 1999.

10. Ribero y Larrea, Historia fabulosa del distinguido caballero don Pelayo Infanzón de la Vega, Quijote
} de la Cantabria, p. 148. 


\section{ANÁLISIS DEL CORPUS}

\subsection{Continuaciones}

\subsubsection{Luis Otero y Pimentel, Semblanzas caballerescas (1886)}

En esta continuación heterodoxa don Quijote y Sancho son recibidos en el palacio de los condes de Vegas Dulces, que convierten a los protagonistas en blanco de sus burlas durante su estancia entre ellos. Así, Sancho Panza será nuevamente elevado a la dignidad de gobernador de la ínsula de Palo Verde.

Tras el final de este segmento narrativo, indudablemente inspirado en el correspondiente a las aventuras de nuestros personajes en su encuentro con los duques en la segunda parte del Quijote cervantino, y después de algunas ficciones tocantes al encantamiento de Dulcinea, don Quijote será desinfectado por una acción sanitaria que pretende preservar a los habitantes de un pueblo de toda contaminación. La burla pesada, pues, se sustancia en la claridad de las intenciones y en su dimensión evidentemente física.

\subsubsection{Antonio Ledesma Hernández, La nueva salida del valeroso caballero don Quijote de la Mancha (1905)}

En esta nueva continuación heterodoxa don Quijote asiste a la representación del Otelo de Verdi, en cuya escena culminante irrumpe en el escenario rescatando a Desdémona de las manos del moro asesino. Don Quijote acaba creyendo que una falsa Dulcinea del Toboso, bajo la cual se esconde una hermosa actriz artísticamente conocida como la Venus de la Georgia, Ilena de admiración por las hazañas de su caballero, regresa desde la Patagonia, a cuyo rey había declarado la guerra por atreverse a pretenderla. La farsante finge sentirse celosa cuando don Quijote toma de la cintura a Desdémona para rescatarla, y le impone usar guantes de esgrima para tocar honestamente a las viudas, damas y doncellas a quienes deba socorrer en el futuro, y como los enamorados intercambian sus cabellos cortados para demostrarse su amor, don Quijote acaba casi calvo como consecuencia de los trasquilones que sufre y sin embargo recibe a cambio lo que, según un encantamiento, ha sido convertido en un basto trozo de estopa.

La falsa Dulcinea prosigue con su burla afirmando que ha sido violentada por el gigantesco rey de los patagones, que la sumió por encantamiento en un sopor que anuló sus fuerzas. Según dice, sin embargo, un venerable anciano a quien afirma haber encontrado en el Sahara, don Quijote puede restituir la virginidad mancillada si supera tres pruebas: «recomponer la unión de Portugal y España, arrancar de Gibraltar la bandera inglesa y reconquistar para la patria española sus perdidas Américas» ${ }^{11}$.

11. Ledesma Hernández, La nueva salida del valeroso caballero don Qujote de la Mancha, p. 300. 
Cumplidas, según cree, las empresas impuestas por la fingida Dulcinea, don Quijote regresa para tomarla en matrimonio en una boda igualmente falsa que oficia el Nigromante, pareja sentimental de la Venus de la Georgia y el matrimonio, falsamente convertido en reyes de España, organiza los asuntos de su reino hasta que sus burladores maquinan una nueva mentira para dar al traste con la unión: Dulcinea debe partir para ayudar a Rusia en la guerra contra Japón dejando a don Quijote como gobernador general, circunstancia que aprovecha para abandonarlo. Es evidente la intención perversa que anima en todo momento a los burladores, artífices de una burla pesada muy elaborada en sus aspectos performativos y ocasionalmente traducida en alguna consecuencia física que pesa sobre el protagonista.

\subsubsection{Juan Manuel Polar, Don Quijote en Yanquilandia (1925)}

Una vez más estamos ante una continuación heterodoxa. Las habilidades de orador de don Quijote no son obstáculo para que sus anfitriones americanos le hagan objeto de burlas. Es destacable, en este sentido, la aventura del desencantamiento del fingido reino de Quivira, a donde debe ir don Quijote para rescatar a una princesa cautiva. Recibidos caballero y escudero por un comitiva de dueñas enlutadas que vapulean a Sancho con sus abanicos, se internan días después en un bosque tenebroso en donde son primero asediados por una «multitud de enmascarados dando saltos y gritos como de demonios escapados del infierno» ${ }^{12}$ y luego sorprendidos por la aparición de un nutrido grupo de ninfas y faunos que precede al estruendo de unos cañones deliberadamente desprovistos de balas para amedrentar a los protagonistas. Ese es el anuncio de la batalla que comienza, nueva burla que consiste en hacer creer a don Quijote que ha salido victorioso de todo un ejército de guerreros que fingen una deshonrosa retirada. La cadena de fingimientos urdida por los anfitriones de don Quijote está evidentemente animada por una intención burlesca inequívocamente malintencionada.

\section{1.4. Trapiello: Al morir don Quijote (2004) y El final de Sancho Panza (2014)}

\subsubsection{Al morir don Quijote}

En la primera de estas dos continuaciones conservadoras que definen a su vez un subsistema recreador perfectamente coherente ${ }^{13}$, reaparecen los duques, que viajan al pueblo de don Quijote con un séquito desmesurado (elefante incluido), movidos por el único deseo de proseguir con sus burlas, ignorantes de la muerte de don Quijote, y finalmente escarmentados por Sansón Carrasco. La burla pesada se neutraliza. 


\section{1.4.2. El final de Sancho Panza y otras suertes}

Con el único ánimo de vengarse de Sansón y Sancho, los duques han obtenido el rango de virreyes del Perú, logran engañar y encarcelar al primero y se proponen también encarcelar al segundo aduciendo también la falsa acusación de ser traficante de esclavos, que pesa igualmente sobre Sansón, como consecuencia de la incorporación al grupo de la negra Guiomar, tratada en realidad como una más de la familia. La burla pesada, inicialmente abortada, adquiere ahora un tono vindicativo de mayores dimensiones.

La duquesa pretende explicarle personalmente a Sancho que «ninguna de las burlas de la ínsula, de las que sin duda ya sabía él por haberlas leído en el libro, fueron hechas con malicia, sino por grato esparcimiento» ${ }^{14}$, pero sus verdaderos propósitos son otros, porque los duques habían quedado escarnecidos en la anónima historia publicada en Cadalso de los Vidrios -obviamente referida a Al morir don Quijote ${ }^{15}$-, atribuida por la duquesa al mismo Carrasco, en donde se recogen las burlas a las que los sometieron el bachiller y el escudero Tosilos ${ }^{16}$ y que fueron conocidos en todo el reino: «Hasta el rey don Felipe nuestro señor leyó esa tercera parte donde se cuenta lo sucedido al morir don Quijote, y rio tanto que le salió una hernia» ${ }^{17}$.

\subsection{AMPLIACIONES}

\subsubsection{Juan Montalvo, Capítulos que se le olvidaron a Cervantes (1895)}

Los momentos de burla pesada se concentran en los capítulos XXIII-XLIV, correspondientes a la estancia de don Quijote y Sancho Panza en la casa de don Prudencio Santivánez, hombre principal. Alli deberá enfrentarse a los falsos gigantes Brandabrando y Brandabrisio, que han raptado a una «princesa de la Mancha» de nombre inicialmente desconocido, que don Quijote identifica de inmediato con Dulcinea. La burla se completa con la caracterización de don Alejo de Mayorga, que adopta el disfraz de un ermitaño que intenta disuadir al caballero de sus intenciones e inmediatamente después se hace pasar por el Caballero del Águila, aunque Sancho Panza descubre que ambos son la misma persona. El Caballero del Águila desafía a don Quijote por el amor de Dulcinea usando de un obstáculo previamente

\footnotetext{
14. Trapiello, El final de Sancho Panza y otras suertes, p. 383.

15. A lo largo de El final de Sancho Panza y otras suertes se menciona con frecuencia un libro publicado en Cadalso de los Vidrios y firmado por «un tal licenciado Medina», a quien se identifica «sin el menor fundamento» (p. 169) con Sansón Carrasco (pp. 169, 170-171 y 225). El escribano señor De Mal, pretendiente de Antonia (la sobrina de don Quijote) desde el primer libro de la serie, comunica por carta a los mal parados duques que el tal licenciado Medina es Sansón Carrasco (p. 225). El contenido de este libro, coincidente con el de Al morir don Quijote, perjudica sin remedio a la salud de Bartolomé Carrasco, padre del bachiller, después de que se lo envíe un remitente anónimo.

16. Ver Trapiello, Al morir don Quijote, capítulo 34.

17. Trapiello, El final de Sancho Panza y otras suertes, p. 385
} 
preparado que se interpone entre ambos y que el primero atribuye a las malas artes de la piruja Leocasta, favorecedora del segundo, sin que la batalla llegue a celebrarse.

Poco después el protagonista escucha una voz de mujer «que cantaba apasionadamente en una ventana» ${ }^{18}$ y que él atribuye sin duda a su Dulcinea cautiva, como confirma ella misma reclamando su libertad, que consigue descolgándose desde la torre en la que está prisionera. Una vez que la tiene a mano descubre que no se trata de la mujer hermosa a la que esperaba liberar, sino de alguien de la peor catadura, de grandes narices y una boca «formidable apuntalada en solo dos colmillos [...] y unos ojos que, por lo grandes, más parecían anteojos», y la aparta de su lado con palabras que no tienen desperdicio: «iFementido aborto!, dijo: tú no eres ni puedes ser la señora a quien yo sirvo: huye de mi presencia, soez demonio, o aquí me has de pagar esta superchería» ${ }^{19}$. Cuando Sancho descubre que la falsa Dulcinea es un hombre, don Quijote vuelve por donde solía atribuyendo el engaño al encantamiento del mago Fristón (no Frestón en este caso) y a tiempo de regresar a la casa de don Prudencio es informado por Alejo de Mayorga de que el gigante Brandabrando ha prendido fuego a su fortaleza para evitar que don Quijote le derrote.

La burla no termina aquí: mientras don Quijote descansa, el marqués de Huagrahuigsa y el barón de Cocentaina, disfrazados de los gigantes Brandabrando y Brandabrisio, irrumpen en su habitación con la fingida Dulcinea, representada por el versátil Alejo de Mayorga, con la intención de castigar a don Quijote, pero este y Sancho Panza se defienden bravamente y los tres burladores se dan a la fuga. Y por si fuera poco, cuando caballero y escudero vuelven a sus camas, aparece en la habitación el falso fantasma de don Benedicto Rochafrida, que pretende satisfacer el antojo de su esposa embarazada, empeñada en morder las orejas de Sancho y de darle «dos o tres docenas de azotes en lo limpio» ${ }^{20}$, a lo que este y don Quijote deciden poner plazo hasta el día siguiente sin que la burla llegue por fin a consumarse, lo que no resta vigor ni contundencia a una buena parte de las burlas pesadas que hemos revisado en la recreación de Montalvo y que acaban cumpliendo su objetivo.

\subsubsection{Julián Motta Salas, Alonso Quijano, el Bueno (1930)}

En esta ampliación se modifican las aventuras del amplio bloque narrativo de la segunda parte del Quijote en donde se desarrolla la estancia de los protagonistas en el palacio de los duques, y tanto las referencias como los personajes guardan una estrecha relación con el modelo, aunque la trama se enriquece y se complica con aportaciones tales como las que tocan al desencantamiento de Dulcinea. En este sentido, en el capítulo XII don Quijote sabe por la predicción de Merlín que Dulcinea sería liberada del hechizo que la retiene en la Ínsula Firme cuando aquel venciese al gigante Orrilo, encarnado por el doctor Recio, como en efecto sucede dos capítulos después. Ilusionado por la alentadora perspectiva de casarse con

18. Montalvo, Capítulos que se le olvidaron a Cervantes, p. 362.

19. Montalvo, Capítulos que se le olvidaron a Cervantes, p. 368.

20. Montalvo, Capítulos que se le olvidaron a Cervantes, p. 392. 
Dulcinea una vez desencantada, don Quijote se rinde a los planes de un futuro dulce que turban las falsas voces mágicas de los farsantes, de nuevo encabezados por maese Recio, quien le recuerda impertinentemente al enamorado cierta cita nocturna con la infanta Celinda y le afea la conducta por la infidelidad en la que incurre.

Don Quijote sabe defender, sin embargo, la honestidad de ese lance a pesar de los amorosos asedios de Celinda, y aparece entonces el fingido cortejo que acompañaba a la desencantada Dulcinea, representada por Altisidora, ante la cual se rinde el enamorado caballero dejando muy claro su renovado amor con palabras encendidas que suscitan la contenida risa de la falsa prometida. Maese Recio, ahora disfrazado de sacerdote, oficia la boda, tras la cual los falsos esposos se retiran a su habitación en la que Dulcinea, cómplice de los burladores, se sustrae al apremio amoroso de don Quijote, deseoso de consumar el matrimonio aduciendo para ello, frente al rechazo de su fingida esposa, una completa relación de ejemplos de los honestos amores comunes en tales circunstancias a la luz de los libros de caballerías. Hastiada por la insistencia de su rendido esposo, y escamada además por las complicaciones que le acarrea la farsa, Altisidora abandona con crueles palabras a don Quijote, tan estupefacto como desengañado.

Sancho Panza actúa de nuevo como garante de la verdad y advierte a su señor del engaño y de la verdadera identidad de los farsantes, pero don Quijote vuelve a atribuir su fracaso a las asechanzas de los encantadores, empeñados en que no consiga «la gloria de haber recuestado y servido a una de las mayores reinas de la tierra ${ }^{21}$. La burla pesada llega a ser en todo caso muy significativamente humillante, y la catadura moral de los burladores queda puesta en evidencia en todo momento.

\subsubsection{Clovis Aymerich, Desconocida aventura de Teresa Panza (1936)22}

Esta breve ampliación narra las desventuras protagonizadas por Teresa Panza en su viaje en busca de su marido Sancho Panza que, según el testimonio de sus vecinos, que urden una bruma de mal gusto, ha sido elevado a la dignidad de príncipe de Apompolí y ha contraído matrimonio con la princesa Pingolatracamundana, dueña de un principado en Flandes. Hasta que se descubre el engaño y se produce el feliz reencuentro de Sancho Panza y Teresa, ambos son sometidos a humillaciones de muy diverso tipo y a cuál más cruel (y escatológica en algún caso), incluida la prisión que sufre Teresa. Las manifestaciones y consecuencias físicas de la burla pesada son especialmente graves y vejatorias. 


\subsubsection{José Camón Aznar, El pastor Quijótiz (1969)}

Don Quijote muere heroicamente por defender la imagen de Dulcinea del Toboso de la hiriente farsa en cuyo transcurso la compañía de Angulo el Malo la presenta como una aldeana fea y grosera, vejación que el protagonista no puede permitirse. La ampliación, de esta forma, tiene un desenlace propio muy diferente al del original, nueva muestra evidente de la libertad creativa propia de sus recreaciones narrativas. No cabe un desenlace más grave para una burla tan eficazmente dirigida a la visión y los valores de don Quijote.

\subsection{IMITACIONES}

\subsubsection{Alonso Jerónimo de Salas Barbadillo, El caballero Puntual (1614)}

Durante las celebraciones posteriores a una comida ofrecida por un letrado de la corte en su huerta junto al Prado de San Jerónimo, don Juan de Toledo, el caballero Puntual, es invitado con las peores intenciones a participar como actor en una «comedia de repente» en la que le corresponde representar el papel de un traidor que asesina a su rey. Atado de pies y manos y a caballo de un burro, y con el pretexto de que debe ser ajusticiado como parte de la representación, le sueltan en la puerta de la calle y al verlo los muchachos la emprenden a palos con el animal, se ríen del jinete (cuya locura celebran) y además le lanzan barro a la cara y le acosan y golpean sin la menor consideración. Para rematar la burla, el hortelano dueño del burro es advertido de que el Puntual se lo ha robado. Al ser motejado de ladrón el Puntual arremete contra aquel, que le da una buena ración de patadas. Como consecuencia de este episodio, la narración parece dejar claro que el Puntual acaba muriendo, pero lo cierto es que reaparece en la segunda parte de la obra (1619) quedando claro que en realidad no hubo tal muerte, sino que don Juan de Toledo fue a Sevilla tras la afrenta recibida.

Allí sufre una nueva burla pesada durante la procesión de Jueves Santo en la que participa, y en la que sus burladores, los mismos a quienes el Puntual ha agasajado antes con una comida, le cambian una y otra vez la cruz que porta como penitencia alternando una muy pesada con otra de una gran ligereza. Una vez descubierta la burla, don Juan no se aparta de la cruz, y sus acompañantes deciden darle una paliza tapándole con una manta de la que se zafa, pero acaba siendo duramente golpeado por su propio criado, con quien se cruza en su huida y a quien acomete al no reconocerlo en medio de la confusión del momento.

Poco después, y ya repuesto, el Puntual es objeto de una nueva burla motivada por su irrefrenable presunción. Ante su baladronada de que ha matado un león, ciertos caballeros de la Universidad y la villa de Alcalá de Henares le enfrentan a uno falso representado por un capigorrón disfrazado con la piel y la cabeza de un león usado para representaciones teatrales, ante cuya presencia huye despavorido retirándose luego a una aldea. 
De nuevo en Alcalá, recibe un falso correo del rey que le insta a servirle con seis lanzas. Salazar, su criado, le mueve a desconfiar y a deponer toda respuesta hasta que, aprovechando un día su ausencia por estar de caza, «un hidalgo de la villa, osado e ingenioso, y que era uno de los conjurados» ${ }^{23}$ practica en la pared de su habitación una falsa entrada por la que entra el mismo capigorrón que se había disfrazado de león días antes caracterizado ahora como don Diego Antonio de Toledo, antepasado del Puntual, y le afea la conducta por la pusilanimidad que muestra a la hora de servir a su rey. Ante una aparición tan persuasiva, don Juan arma los seis caballeros falsamente reclamados por el mandato real y, con un ridículo alarde que solo sirve para ponerlo en evidencia, los despacha a la corte, siendo nuevamente desengañado por el fiel Salazar, que le convence para que abandoné Alcalá.

Retirado a su Toledo natal, vuelve a recibir una nueva burla pergeñada por don Antonio, un estudiante que es su rival en las pretensiones del amor de una noble señora de la villa. Acompañado de sus amigos, se sitúa una noche bajo la ventana del Puntual, en donde revela las señales del cometa que, según parece, anuncia su inminente muerte. Lejos de entregarse al arrepentimiento y a la prudencia propios de quien va a morir, don Juan decide buscar cuanto antes la muerte y se entrega a una vida temeraria y pendenciera en uno de cuyos lances es mortalmente herido. Una vez más es Salazar quien, en su convalecencia, desengaña al Puntual con palabras que dejan muy clara la facilidad con la que su señor concita la burla y el desprecio ajenos.

Don Juan acaba reponiéndose, pero vuelve a su misma forma de vida y es expulsado de Toledo para continuar en los reinos de Aragón nuevas aventuras que, según el narrador, serán objeto de una tercera parte que no llegó a publicarse. Son muy evidentes en el Puntual los rasgos característicos de la burla pesada y lo son igualmente sus consecuencias físicas, en algún caso singularmente contundentes para el protagonista.

\subsubsection{Rafael Crespo, Don Papís de Bobadilla (1829)}

En esta imitación ideológicamente orientada en contra de los valores del enciclopedismo ilustrado, destacamos como ejemplo de burla pesada la peripecia basada en la invención de la cabeza encantada que sorprende a los protagonistas en casa de don Antonio Moreno durante su estancia en Barcelona (Quijote, II, 62). En la imitación de Crespo, Papís es enterrado hasta el cuello por Zacarías, un montañés socarrón, y queda convertido en una ridícula «cabeza parlante» y pidiendo auxilio hasta que Crispín, el trasunto de Sancho Panza en el Papís, lo desentierra y lo libera ${ }^{24}$. No cabe ninguna duda del grave alcance físico de la burla y de sus consecuencias humillantes. 


\subsubsection{Luis Antón del Olmet, La postrera salida de don Quijote (1910)}

El hidalgo don Rodrigo Meléndez, recto y de nobles intenciones, resulta pesadamente embromado por unos malintencionados estudiantes de Santiago de Compostela, que urden la triste historia de la desvalida Efigenia, cruelmente tratada por su perversa madrastra, y publican en un periódico una nota que mueve a don Rodrigo a reaccionar en su favor creyendo que ha iniciado con su protegida a partir de entonces un prometedor noviazgo que se mantiene falsamente mediante un intercambio de cartas escritas por sus burladores. La farsa acaba desgraciadamente cuando el enamorado, días antes de la boda que iba a contraer con la inventada Efigenia, destapa el cruel engaño. La burla pesada cumple su objetivo humillante y cruel.

\subsubsection{José Larraz, ¡Don Quijancho, maestro! (1969)}

El avieso, deforme e indiscreto Quintín Recacho, asiduo a la tertulia de Pedro Bravo en Segovia, urde una mascarada con la cual pretende burlarse de Roberto Núñez de los Godos y Hasparren, el protagonista de la recreación de Larraz. La burla consiste en leer un texto que aborda la castidad de don Quijote de la Mancha poniéndola en relación con la actitud generosa y desprendida que muestra Roberto para con una anciana enferma que vivía cerca del río Clamores con «una lozana jamona, foránea, de no muy buena fama» ${ }^{25}$ cuyos favores eran su verdadero objetivo según la perversa interpretación que sugiere Recacho. En el escrito en cuestión don Quijote es acusado de lujuria e infidelidad a Dulcinea por el episodio de Maritornes y por el abrazo que dio en su momento a la fingida princesa Micomicona. Roberto responde con cajas destempladas defendiendo la honestidad de don Quijote frente a quienes la ponen en entredicho y además amenaza indirectamente a Recacho con desafiarle a un duelo, respuesta ante la que los muñidores de la burla cejan en su empeño.

Lo anterior es insignificante ante el nuevo asedio de Recacho, empeñado en conseguir que la bella Consuelo, de quien ambos se han enamorado, se aleje de Roberto, su rival en sus pretensiones amorosas. Con esa intención, Recacho adopta una noche la falsa identidad del fantasma de don Quijote, quien afirma que es además el abuelo del aturdido Roberto. Respondiendo a las instancias del farsante, el protagonista encuentra entre los papeles de la familia unos documentos falsos, pretendidamente autógrafos, que el burlador había logrado introducir previamente en casa de su enemigo sin que nadie se diera cuenta y que hacen creer a Roberto que, en efecto, es descendiente de don Quijote.

La fuerza de este engaño es tan grande que el protagonista comienza un grotesco proceso de quijotización coherente con el legado de su ancestro: compra en el Rastro madrileño una armadura del siglo XVI que completa con un lanzón y dos espadas y hace saber a Consuelo, con un estilo propio de su modelo y pariente, que ha decidido posponer dos años la petición de su mano. Decepcionada, Consuelo

25. Larraz, ¡Don Quijancho, maestro!, p. 174. 
acaba casándose tiempo después con Quintín Recacho, que triunfa en sus pretensiones a causa de su burla pesada mientras que Roberto persiste en su determinación velando las armas en la iglesia de la Vera Cruz y protagonizando dislates que no solo merman su fama, sino también su integridad física. La elaboración performativa de la burla pesada es muy especialmente destacable, y sus graves consecuencias en el comportamiento y el carácter de Roberto no dejan lugar a la menor duda.

\subsubsection{Andrés Amorós, La vida nueva de Alfonso de Quesada (2006)}

A costa de su talante y de su amor por la Beatriz de Dante, con quien cree haberse encontrado en Salamanca y en Florencia, el profesor Alfonso de Quesada es objeto de la burla urdida en Almagro por unos marqueses so capa de un homenaje en cuyo transcurso aparece una falsa Beatriz cuya presencia, unida a la intención burlesca de sus anfitriones que el protagonista capta con dolorida perspicacia, le hacen sentir muy incómodo y confiesa experimentar «una sensación muy clara de vergüenza, de estar contribuyendo a algo innoble» ${ }^{26}$ (156). La falsa Beatriz también se presenta en la habitación de Alfonso con la mala intención de confesarle su amor y fingir que desea seducirle, pero el diálogo entre Alfonso y su fiel amigo Santi, trasunto de Sancho Panza, parece sugerir sutilmente que lo que empezó como una burla acabó de otra manera. El tono grave de la burla, sea cual sea el resultado final, está muy claro al menos en su intención.

\section{CONCLUSIONES}

En conclusión, parece claro que, frente a la burla eutrapélica, la burla pesada se caracteriza por el grado de perversión que anima a los burladores y sus consecuencias morales, actitudinales y físicas (alguna vez fatales), que suponen un evidente perjuicio para los protagonistas.

La burla pesada está presente en las tres categorías principales de las recreaciones narrativas hispánicas del Quijote, y por lo que respecta a las continuaciones, es por ahora más común en las ortodoxas (especialmente en la singular modalidad de las resurrecciones ${ }^{27}$ ) que en las conservadoras, y parece más presente en las recreaciones publicadas en España (Salas Barbadillo, Crespo, Otero y Pimentel, Ledesma, Aymerich, Antón del Olmet, Larraz, Camón Aznar, Amorós y Trapiello) que en las hispanoamericanas (Montalvo, Polar y Motta Salas).

La presencia recurrente de la nobleza en los episodios burlescos, como consecuencia de la inspiración del bloque narrativo definido por la estancia de don Quijote y Sancho en el palacio de los duques en el original cervantino, es especialmente fecunda, como vemos en la ampliación de Motta Salas y las continuaciones de Trapiello, en las cuales reaparecen los modelos cervantinos que se convierten en 
burladores burlados. Otero y Pimentel opta por condes en su continuación, Montalvo en su ampliación por barones y marqueses y algún caballero principal cuya condición nobiliaria no se especifica, y Amorós por unos marqueses en su imitación.

La influencia de Dulcinea o su personaje femenino equivalente es muy frecuente en los episodios de burla pesada. Las Dulcineas fingidas (sin olvidar nunca que la Dulcinea fingida por excelencia es la que se inventa Sancho Panza en el Quijote) aparecen en las continuaciones de Otero y Pimentel y Ledesma y en las ampliaciones de Montalvo, Motta Salas y Camón Aznar, en este último caso con una dimensión evidentemente trágica. La figura de la princesa sin nombre que necesita protección también aparece en la continuación de Polar, y la necesidad de proteger a la mujer desvalida inspira la intervención del protagonista de la imitación de Antón del Olmet.

En todas las recreaciones analizadas menos en las de Aymerich, Antón del Olmet y Amorós, se hace presente la invención malintencionada de la magia o lo preternatural, siempre en relación con el destino del caballero andante y su engranaje en lo que yo denomino «historia trascendente» 28 , y en casi todas (Salas Barbadillo, Crespo, Otero y Pimentel, Antón del Olmet, Ledesma, Polar, Larraz y Amorós), como es lógico, primero es don Quijote o el personaje que lo recrea quien sufre las principales agresiones burlescas, y a continuación es Sancho Panza el principal objeto de burla pesada en las ampliaciones de Aymerich y Montalvo (fallida en este último caso), y junto a Sansón Carrasco en las continuaciones de Trapiello. Por lo que respecta a los personajes, hay que significar también el peso de Sancho Panza en las ampliaciones de Montalvo y Motta Salas o de Salazar, su trasunto en la imitación de Salas Barbadillo, a la hora de balancear la percepción de don Quijote o desmontar la perversión de los burladores.

Habrá que seguir en fin, atentos a las huellas de la burla pesada en las recreaciones que vendrán, porque podrán arrojar alguna buena pista sobre las futuras connotaciones sociales y estéticas de esa facilidad que parecen tener don Quijote y los personajes que en él se inspiran para concitar la mala fe de sus semejantes, sin que deje de levantarse una y otra vez de sus adversidades como ese hombre escarnecido y cubierto de heridas que, según nos recuerda la letra de «The impossible dream», la inolvidable balada de Man of la Mancha de Leigh, Wasserman y Darion, seguirá haciendo que el mundo sea mejor.

\section{BiBLIOGRAFÍA}

Amorós, Andrés, La vida nueva de Alfonso de Quesada, Madrid, Castalia, 2006.

Arellano, Ignacio, «Las máscaras de Demócrito: en torno a la risa en el Siglo de Oro», en Demócrito áureo. Los códigos de la risa en el Siglo de Oro, ed. Ignacio Arellano y Victoriano Roncero, Sevilla, Renacimiento, 2006, pp. 329-357. 
Arellano, Ignacio, y Roncero, Victoriano (eds.), en Demócrito áureo. Los códigos de la risa en el Siglo de Oro, Sevilla, Renacimiento, 2006.

Aristóteles, Ética nicomaquea, trad. Julio Pallí Bonet, Madrid, Gredos, 1985.

Antón del Olmet, Luis, La postrera salida de don Quijote, Madrid, Los Contemporáneos, 77, 17 de junio de 1910.

Aymerich, Clovis, Desconocida aventura de Teresa Panza, Barcelona, Ramón Sopena, 1936.

Camón Aznar, José, El pastor Quijótiz, Madrid, Espasa-Calpe, 1969.

Close, Anthony, «La dicotomía burlas / veras como principio estructurante de las novelas cómicas del Siglo de Oro», en Demócrito áureo. Los códigos de la risa en el Siglo de Oro, ed. Ignacio Arellano y Victoriano Roncero, Sevilla, Renacimiento, 2006, pp. 113-142.

Covarrubias, Sebastián de, Tesoro de la lengua castellana o española [1611], ed. Ignacio Arellano y Rafael Zafra, Madrid/Frankfurt am Main, Iberoamericana/ Vervuert, 2006.

Crespo, Rafael, Don Papís de Bobadilla, o sea defensa del cristianismo y crítica de la seudofilosofía, Zaragoza, Polo y Monge, 1829.

Darío, Rubén, «D. Q.» [1899], en Cuentos fantásticos, Madrid, Alianza Editorial, 1976, pp. 61-65.

Delgado, Jacinto María, Adiciones a la historia del ingenioso hidalgo don Quijote de la Mancha, en que se prosiguen los sucesos ocurridos a su escudero el famoso Sancho Panza, escritas en arábigo por Cide Hamete Benengeli, y traducidas al castellano con las memorias de la vida de este, Madrid, en la imprenta de Blas Román, 1786.

Étienvre, Jean-Pierre, «Primores de lo jocoserio», Bulletin Hispanique, 106.1, 2004, pp. 235-252.

Fernández de Avellaneda, Alonso, Segundo tomo del ingenioso hidalgo don Quijote de la Mancha [1614], ed. Luis Gómez Canseco, Madrid, Real Academia Española, 2014.

Larraz, José, ¡Don Quijancho, maestro!, Madrid, Espasa-Calpe, 1969.

Ledesma Hernández, Antonio, La nueva salida del valeroso caballero don Quijote de la Mancha, Barcelona, Casa Editorial Lezcano, 1905.

López Navia, Santiago, La ficción autorial en el «Quijote» y en sus continuaciones e imitaciones, Madrid, Universidad Europea de Madrid/CEES Ediciones, 1996.

López Navia, Santiago, Inspiración y pretexto. Estudios sobre las recreaciones del «Quijote», Madrid/Frankfurt am Main, Iberoamericana/Vervuert, 2005.

López Navia, Santiago, «Cide Hamete Benengeli y la conciencia de la historia en Al morir don Quijote de Andrés Trapiello», Monteagudo, 20, 2015, pp. 55-72. 
López Navia, Santiago, «Cide Hamete Benengeli y la conciencia de la historia en El final de Sancho Panza y otras suertes de Andrés Trapiello (2014)», en Cervantès quatre siècles après. Nouveaux objets, nouvelles aproches, ed. Emmanuel Marigno, Carlos Mata Induráin y Marie-Hélène Maux, Binges, Éditions Orbis Tertius, 2017, pp. 151-176.

Martínez Fernández, José Enrique, «Burla, sátira y humor en Fray Gerundio de Campazas (huellas de la comicidad carnavalesca)», Epos, 15, 1999, pp. 175-197.

Montalvo, Juan, Capítulos que se le olvidaron a Cervantes [1895], ed. Ángel Esteban, Madrid, Cátedra, 2004.

Motta Salas, Julián, Alonso Quijano, el Bueno (Don Quijote en Villaseñor), Bogotá, Editorial Minerva, 1930.

Otero y Pimentel, Luis, Semblanzas caballerescas o Las nuevas aventuras de don Quijote de la Mancha, La Habana, Tipografía de El Eco Militar, 1886.

Pedrosa, José Manuel, El cuento popular en los Siglos de Oro, Madrid, Ediciones del Laberinto, 2004.

Polar, Juan Manuel, Don Quijote en Yanquilandia, Cartagena, Editorial Juvenilia, 1925.

Ribero y Larrea, Alonso Bernardo, Historia fabulosa del distinguido caballero don Pelayo Infanzón de la Vega, Quijote de la Cantabria, Madrid, en la imprenta de la viuda de Ibarra, 1792.

Roncero López, Victoriano, «El humor y la risa en las preceptivas de los Siglos de Oro», en Demócrito áureo. Los códigos de la risa en el Siglo de Oro, ed. Ignacio Arellano y Victoriano Roncero, Sevilla, Renacimiento, 2006, pp. 285-328.

Salas Barbadillo, Alonso Jerónimo [1614], El caballero Puntual, ed. José Enrique López Martínez, Madrid, Real Academia Española, 2016.

Siñeriz, Juan Francisco, El Quijote del siglo XVIII o historia de la vida y hechos, aventuras y fazañas de Mr. Le-Grand, Madrid, Imprenta de don Miguel de Burgos, 1836.

Trapiello, Andrés, Al morir don Quijote, Barcelona, Destino, 2004.

Trapiello, Andrés, El final de Sancho Panza y otras suertes, Barcelona, Destino, 2014. 